\title{
Peculiar NCCT Brain Picture in Polycythemia
}

\section{Rohit Bhoil}

\section{ABSTRACT}

This is a case of polycythemia presenting with headache and showing hyperdense cerebral vasculature and dural sinuses thereby simulating the appearance of a contrast enhanced computed tomography (CT) on plain films.

Keywords: Hyperdense cerebral vasculature, Hyperdense sinuses, Noncontrast computed tomography (NCCT) brain, Polycythemia, Increased hematocrit.

How to cite this article: Bhoil R. Peculiar NCCT Brain Picture in Polycythemia. J Postgrad Med Edu Res 2014;48(4):197-198.

Source of support: Nil

Conflict of interest: None

\section{INTRODUCTION}

Polycythemia is defined as an increase in the total cell mass of the blood. This increase in cellular mass causes an increase in the viscosity of blood which may lead to venous thrombosis including that of cerebral veins and sinuses, producing on noncontrast computed tomography (NCCT) head hyperattenuation of the involved segments. ${ }^{1}$ However, the hemoconcentration has seen in polycythemia may itself cause the brain vasculature to appear hyperdense on NCCT head. ${ }^{2}$

Thus, polycythemia on NCCT head may present as hyperdense vasculature either as a result of hemoconcentration or may lead to venous thrombosis and consequent hyperdensity of the vessels involved.

\section{CASE REPORT}

A 64-year-old male chronic smoker presented in the emergency with complaint of headache since the past 2 weeks which aggravated in intensity since the last 1 day. No neurological deficit was present.

Based on the initial complaint of severe headache, the patient was referred to the Department of Radiodiagnosis for NCCT head to rule out subarachnoid hemorrhage.

Noncontrast computed tomography head findings showed hyperdense cerebral venous sinuses and cerebral

\section{Resident}

Department of Radiodiagnosis, Dr Rajendra Prasad Government Medical College, Tanda, Himachal Pradesh, India

Corresponding Author: Rohit Bhoil, Resident, Department of Radiodiagnosis, Dr Rajendra Prasad Government Medical College, Tanda, Himachal Pradesh, India, Phone: 9418021905 e-mail: rohitbhoil@gmail.com vasculature; findings were suggestive of hyperattenuating cerebral vasculature including large and small branches of circle of Willis (Fig. 1); and dural venous sinuses (Fig. 2) (appearance mimicking contrast enhanced computed tomography (CECT) on an NCCT head).

There was no feature suggestive of any edema, bleed, infarct or mass in either supratentorial or infratentorial compartment.

The NCCT head picture of generalized hyperdense cerebral vasculature without any other abnormality indicated raised blood hemoglobin concentration which was subsequently confirmed by the patient's complete blood count which showed hemoglobin of $22 \mathrm{gm} / \mathrm{dl}$ with a hematocrit of $74 \%$. His white blood cell (WBC) count was $11,600 / \mu 1$ and platelet count was $51,000 / \mu 1$.

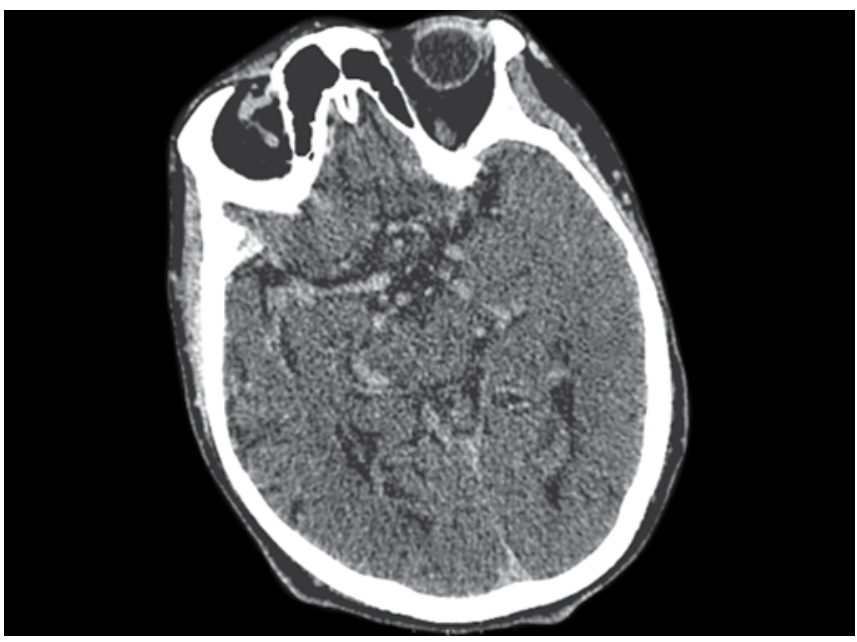

Fig. 1: Hyperdense cerebral vasculature on non-contrast CT scan of head simulating a CECT

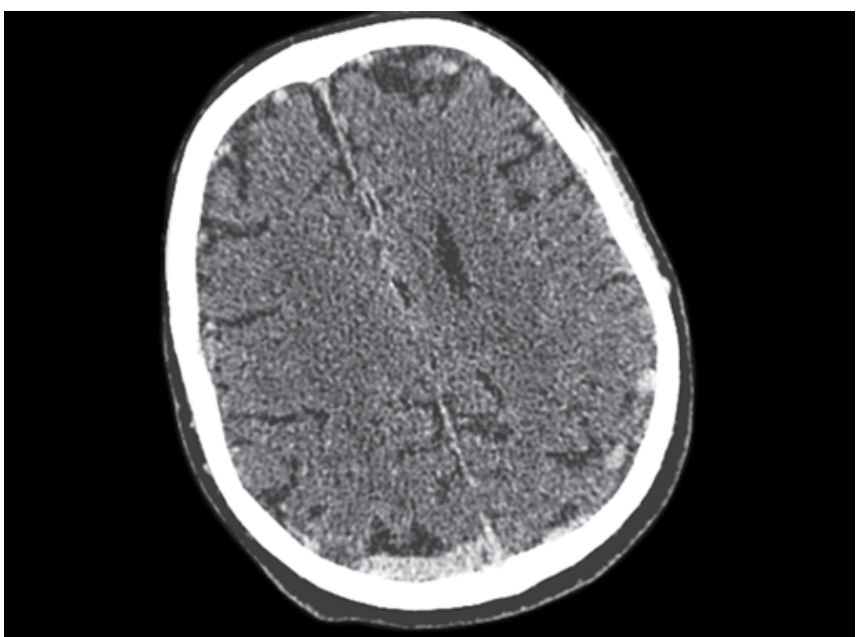

Fig. 2: NCCT head showing hyperdense venous sinus 
Based on these investigations including NCCT head picture, an impression of polycythemia (secondary to chronic pulmonary disease) was made.

\section{DISCUSSION}

There occurs a linear relationship between attenuation on computed tomography (CT) and hematocrit, hemoglobin concentration and protein content. ${ }^{3}$ Flowing blood at a hematocrit of $45 \%$ measures approximately 40 HU. In normal adults hematocrit ranges from 42 to $52 \%$ and 37 to $47 \%$ in normal neonates. Therefore, cerebral vasculature appears isodense or minimally hyperdense in the normal adult, as the normal adult gray matter measures approximately 39 HU. A linear relationship exists between the hemoglobin level and the CT value of the dural sinuses, indicating that the increased density of vasculature on nonenhanced computed tomography (NECT) brain is a sign of a high hemoglobin level. ${ }^{4}$

Polycythemia can cause diffuse hyperintensity of blood vessels including circle of Willis and dural venous sinuses when hematocrit exceeds $60 \%$. In venous sinus thrombosis, there is selective hyperintensity of dural venous sinuses. Both can present as an increase in CT attenuation of cerebral venous sinuses and it is of vital importance to differentiate them because of the possibility of their coexistence. ${ }^{5}$

Definite differentiation between the two can be done by magnetic resonance imaging (MRI) (time of flight venography), CT venography or catheter venography. ${ }^{2}$

The ratio of CT attenuation of cerebral venous sinuses to hematocrit might be useful for differentiating hyperintensity due to polycythemia and venous sinus thrombosis. Attenuation of more than $70 \mathrm{HU}$ is suggestive of venous sinus thrombosis and less than $70 \mathrm{HU}$ is suggestive of polycythemia. ${ }^{6}$

\section{CONCLUSION}

Polycythemia may simulate as well as cause venous thrombosis, confounding the NCCT findings. Moreover, the two conditions may co-exist. Therefore, the cause of hyperdense vasculature on NCCT head in polycythemia should be carefully ruled out by magnetic resonance (MR), computed tomography (CT) or catheter venography.

\section{REFERENCES}

1. Rodallec MH, Krainik A, Feydy A, Helias A, Colombani JM, Julles MC, et al. Cerebral venous thrombosis and multidetector CT angiography: tips and tricks. Radiographics 2006;26(Suppl 1):S5-S18.

2. Healy JF, Nichols C. Polycythemia mimicking venous sinus thrombosis. Am J Neuroradiol 2002;23(8):1402-1403.

3. Osborn AG. Diagnostic neuroradiology. 2nd Indian reprint. Mosby 2007;158:388.

4. Ben Salem D, Osseby GV, Rezaizadeh-Bourdariat K, Pastural G, Martin D, Brunotte F, et al. Spontaneous hyperdense intracranial vessels seen on CT scan in polycythemia cases. J Radiol 2003;84(5):605-608.

5. Gayathri S, Prasad A, Sachdeva N, Baruah BP, Aggarwal S. Unique features of polycythemia observed on plain non contrast CT scan of head. J Pediatr Neurosci 2010;5(1):27-29.

6. Black DF, Rad AE, Gray LA, Campeau NG, Kallmes DF. Cerebral venous sinus density on noncontrast CT correlates with hematocrit. Am J Neuroradiol 2011;32(7):1354-1357. 